\title{
Application of HEC-RAS in floating bridge Calculation of the backwater height
}

\author{
Tian $\mathrm{Wu}^{1, \mathrm{a}}$, ${ }^{*}$ Zhao Zheng ${ }^{1, \mathrm{~b}}$, Wenlong $\mathrm{Ma}^{1, \mathrm{c}}$ \\ ${ }^{1}$ Henan Yellow River Reconnaissance, Design and Research Institute, ZhengZhou 450003, China \\ a43456047@qq.com, b zzcollan@163.com, c 281271891@qq.com
}

Keywords: HEC-RAS, floating bridge, backwater height

Abstract: HEC-RAS is a very powerful and practical software which was developed by the Hydrologic Engineering Center. In this paper, this software is introduced to calculate the backwater height which is caused by a floating bridge on the yellow river. We can easily obtain the backwater height through using this software.

\section{Introduction}

Floating bridge is one of the most ordinary block water buildings in river channels, the backwater height is always calculated with the method of the railway, highway hydrological survey design specification, apart from these empirical formula methods, Bernoulli equation, formula of Henderson, Yarnell formula are frequently recommended to obtain the backwater height.

HEC-RAS was developed by the Hydrologic Engineering Center. This software allows you to perform one-dimensional steady flow, unsteady flow calculations, sediment transport/mobile bed computations and water temperature modeling. The bridge modeling was introduced in this powerful software. In this paper, a calculation example was introduced to explain how to use HEC - RAS to obtain the backwater height of a floating bridge.

\section{The basic principle of HEC-RAS}

HEC-RAS is currently capable of performing one-dimensional water surface profile calculations for steady gradually varied flow in natural or constructed channels. Subcritical, supercritical, and mixed flow regime water surface profiles can be calculated. The Energy equation (Eq.1), which, has been written as follows, the basic elements has been reflected in Figure 1:

$$
Z_{2}+Y_{2}+\frac{a_{2} V_{2}^{2}}{2 g}=Z_{1}+Y_{1}+\frac{a_{1} V_{1}^{2}}{2 g}+h_{e}
$$

Where: $\mathrm{Z}=$ elevation of the main channel invert, $\mathrm{Y}=$ depth of water at cross section, $\mathrm{V}=$ average velocities (total discharge/ total flow area), $\alpha=$ velocity weighting coefficient, $\mathrm{g}=$ gravitational acceleration, $\mathrm{h}_{\mathrm{e}}=$ energy head loss.

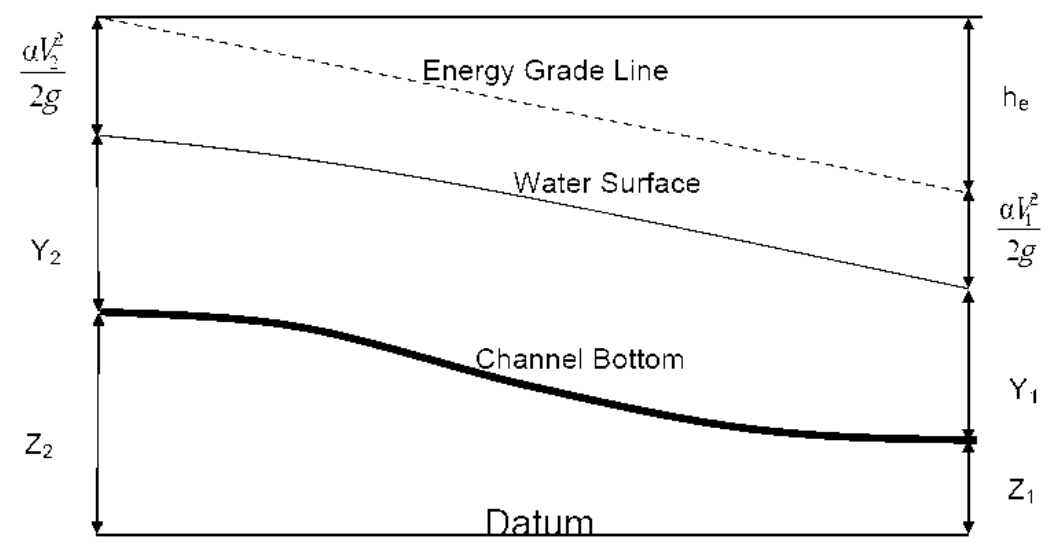

Figure 1. Representation of Terms in the Energy Equation 
The energy head loss $\left(h_{\mathrm{e}}\right)$ between two cross sections is comprised of friction losses and contraction or expansion losses. The equation for the energy head loss is as follows:

$$
h_{e}=L \overline{S_{f}}+C\left|\frac{\alpha_{2} V_{2}}{2 g}-\frac{\alpha_{1} V_{1}}{2 g}\right|
$$

Where: $L=$ discharge weighted reach length, $\overline{S_{f}}=$ representative friction slope between two sections, $\mathrm{C}=$ expansion or contraction loss coefficient.

The distance weighted reach length, $\mathrm{L}$, is calculated as:

$$
L=\frac{L_{1 o b} Q_{l o b}+L_{c h} Q_{c h}+L_{r o b} Q_{r o b}}{Q_{l o b}+Q_{c h}+Q_{r o b}}
$$

Where: $L_{1 o b}, L_{c h}, L_{\text {rob }}=$ cross section reach lengths specified for flow in the left overbank, main channel, and right overbank, respectively, $Q_{1 o b}+Q_{c h}+Q_{\text {rob }}=$ arithmetic average of the flows between sections for the left overbank, main channel, and right overbank, respectively.

The determination of total conveyance and the velocity coefficient for a cross section requires that flow be subdivided into units for which the velocity is uniformly distributed. The approach used in HEC-RAS is to subdivide flow in the overbank areas using the input cross section $\mathrm{n}$ value break points (locations where n-values change) as the basis for subdivision (Figure 2). Conveyance is calculated within each subdivision from the following form of Manning's equation:

$$
\begin{aligned}
& Q=K S_{f}^{1 / 2} \\
& K=\frac{1}{n} A R^{2 / 3}
\end{aligned}
$$

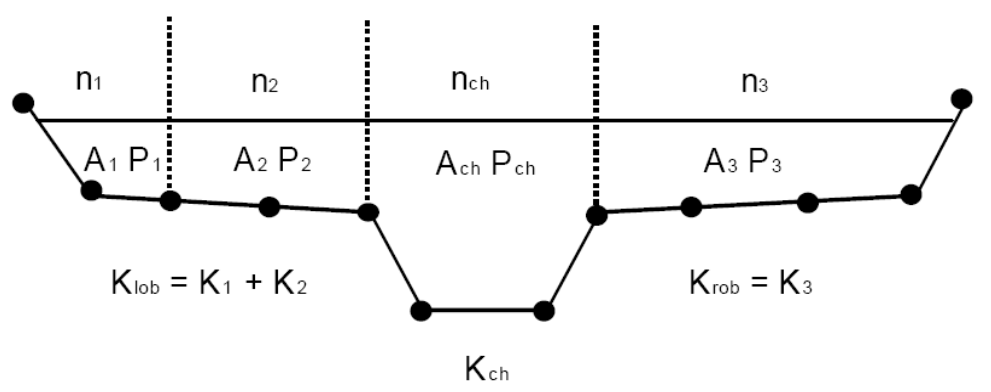

Figure 2. HEC-RAS Default Conveyance Subdivision Method

The velocity coefficient, $\alpha$, is computed based on the conveyance in the three flow elements: left overbank, right overbank, and channel. It can also be written in terms of conveyance and area as in the following equation:

$$
\alpha=\frac{\left(A_{t}\right)^{2}\left[\frac{K_{l o b}^{3}}{A_{l o b}^{2}}+\frac{K_{c h}^{3}}{A_{c h}^{2}}+\frac{K_{r o b}^{3}}{A_{r o b}^{2}}\right]}{K_{t}^{3}}
$$

Where: $A_{t}=$ total flow area of cross section, $A_{l o b}, A_{c h}, A_{r o b}=$ flow areas of left overbank, main channel and right overbank, respectively, $K_{t}=$ total conveyance of cross section, $K_{l o b}, K_{c h}, K_{r o b}=$ conveyances of left overbank, main channel and right overbank, respectively.

Friction loss is evaluated in HEC-RAS as the product of $S_{f}$ and L (Equation 2), where $S_{f}$ is the representative friction slope for a reach and $\mathrm{L}$ is defined by Equation 3. The friction slope (slope of the energy gradeline) at each cross section is computed from Manning's equation as follows:

$$
S_{f}=\left(\frac{Q}{K}\right)^{2}
$$

The bridge routines utilize four user-defined cross sections in the computations of energy losses due to the structure. During the hydraulic computations, the program automatically formulates two 
additional cross sections inside of the bridge structure. A plan view of the basic cross section layout is shown in Figure 3.

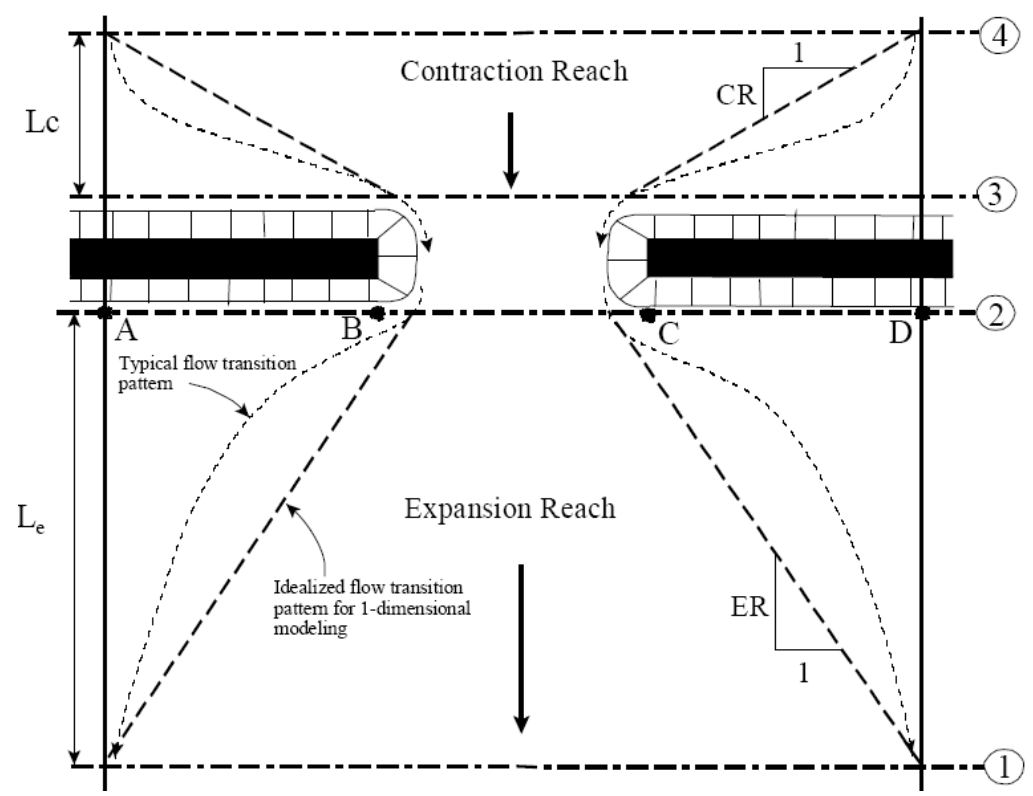

Figure 3 Cross Section Locations at a Bridge

\section{The application on a floating bridge of HEC-RAS}

The basic situation. A floating bridge will be constructed on the yellow river. The design length of floating bridge is $650 \mathrm{~m}$, the design width of the bridge foundation is $10 \mathrm{~m}$.

Boundary conditions. The hydraulic conditions of one dimensional model should include the discharge of the cross section at the upstream boundary and the water level of the cross section at the downstream boundary. The hydraulic conditions are listed in the table 1.

Table 1. The hydraulic conditions of the floating bridge

\begin{tabular}{|c|c|c|c|c|}
\hline $\begin{array}{c}\text { The upstream } \\
\text { condtions }\end{array}$ & discharge $\left(\mathrm{m}^{3} / \mathrm{s}\right)$ & 1000 & 2000 & 3000 \\
\hline $\begin{array}{c}\text { The downstream } \\
\text { condtions }\end{array}$ & water level(m) & 60.32 & 61.00 & 61.63 \\
\hline
\end{tabular}

Calculation cases. The two typical calculation cases are presented to analysis the backwater height will be caused by the floating bridge.

Case1: present condition means that there is no bridge in the river.

Case2: the floating bridge has been constructed in the river.

By comprising with the water profiles of both two cases of above, we can obtain the backwater height of the floating bridge.

Calculation results. The backwater heights of various discharges have been listed in table 2 and the water profiles have been displayed in Figure 4. We can acquire that the maximum of backwater height, which is $0.07 \mathrm{~m}$, will occur when the discharge is $3000 \mathrm{~m}^{3} / \mathrm{s}$.

Table 2. the results of backwater and length

\begin{tabular}{|c|c|c|c|}
\hline discharge $\left(\mathrm{m}^{3} / \mathrm{s}\right)$ & 1000 & 2000 & 3000 \\
\hline backwater height(m) & 0.03 & 0.05 & 0.07 \\
\hline backwater length $(\mathrm{m})$ & 349 & 582 & 815 \\
\hline
\end{tabular}




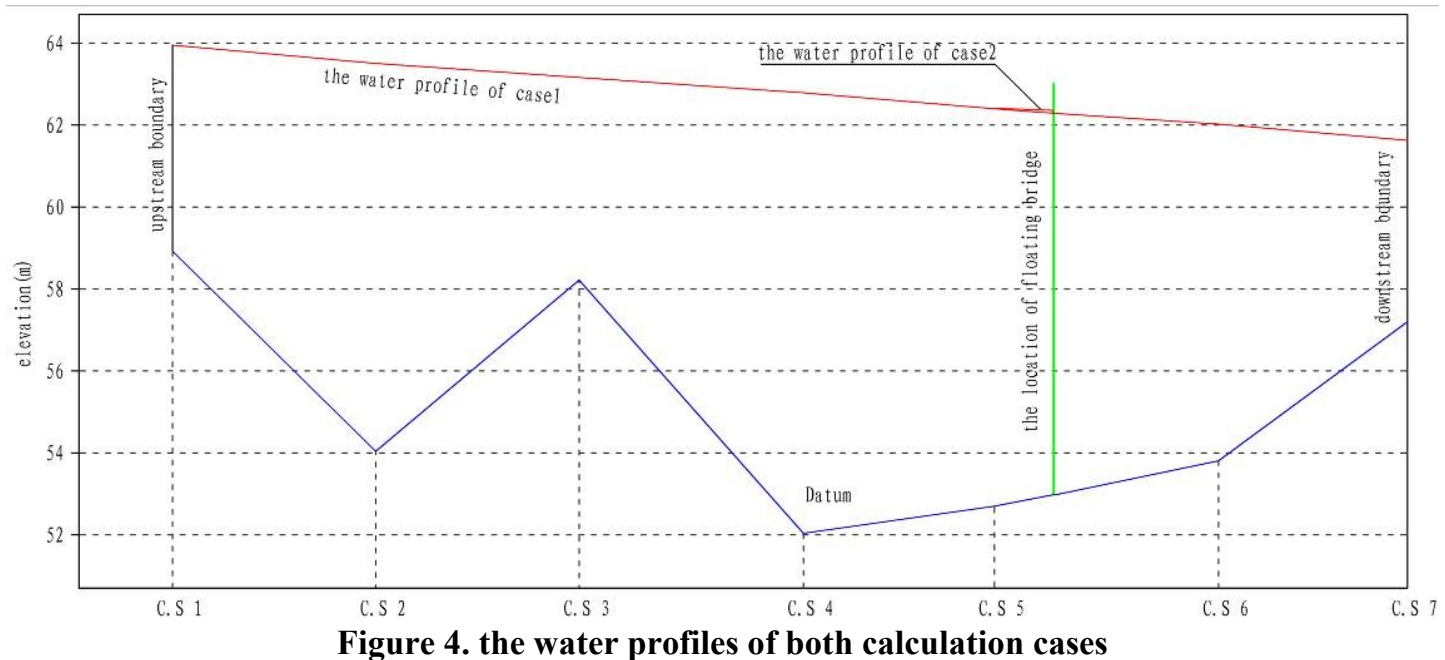

\section{Conclusions}

(1) HEC-RAS is a very powerful and practical software in caculating the water profiles.

(2) Through comparing with both cases we have presented, it is convenient for us to obtain the backwater height which is caused by floating bridge.

\section{References}

[1] Wu Chigong: Hydraulics [M]. Beijing: Higher Education Press, 2008 (in Chinese),

[2] Li Wei: Handbook of Hydraulic Calculations [M]. Beijing: China Water \& Power Press, 2006 (in Chinese). 